\title{
ARTIGO
}

\section{LÍNGUAS ADICIONAIS EM ESCOLAS PÚBLICAS: DISCUSSÃO A PARTIR DE UM CENÁRIO INTERCULTURAL}

\author{
MARISTELA PEREIRA FRITZEN - (https://orcid.org/0000-0001-8747-8426) * \\ Universidade Regional de Blumenau, Santa Catarina, Brasil \\ ANA CAROLINA DE SOUZA NAZARO - (https://orcid.org/0000-0001-6391-6284) ** \\ Universidade Regional de Blumenau, Santa Catarina, Brasil
}

RESUMO: O presente artigo tem por objetivo discutir dados parciais de uma pesquisa mais abrangente que buscou analisar a oferta de línguas adicionais na educação básica em um cenário marcado historicamente pela interculturalidade, a Microrregião de Blumenau, Santa Catarina. Estudos anteriores já apontaram a presença de línguas de imigração nessa região, o que justifica a necessidade de se traçar um perfil das línguas oferecidas no currículo escolar dos sistemas públicos de ensino. Os procedimentos metodológicos incluíram um levantamento de dados nos quinze municípios que compõem a referida região, por meio de um questionário. A partir desse levantamento foi possível conhecer a situação de cada município no tocante às línguas oferecidas nas escolas e as recentes políticas linguísticas locais. A análise dos registros indica o pouco investimento nas línguas de imigração ainda presentes na Microrregião, bem como a necessidade de se discutir o papel da escola diante do plurilinguismo na contemporaneidade.

Palavras-chave: Línguas adicionais; Línguas de imigração; Educação básica; Microrregião de Blumenau.

ADDITIONAL LANGUAGE TAUGHT IN PUBLIC SCHOOLS: DISCUSSION FROM AN INTERCULTURAL SCENARIO

ABSTRACT: This article aims to discuss partial data of a more comprehensive survey that analyzed the offer of additional languages in the primary education, in a scenario historically characterized by intercultural aspects: the Micro-region of Blumenau, Santa Catarina. Previous studies have pointed the presence of immigration languages in the region, which justifies

\footnotetext{
"Doutora em Linguística Aplicada pela Universidade Estadual de Campinas (Unicamp). Professora do Programa de Pós-Graduação/Mestrado em Educação e do Departamento de Letras da Universidade Regional de Blumenau(FURB). Membro dos grupos de pesquisa "Vozes na Escola" e "Linguagens e Letramentos na Educação". E-mail: < mpfritzen@gmail.com>

" Licenciada em Letras pela Universidade Regional de Blumenau (FURB) e Professora da Educação Básica. E-mail:< ana.nazaro@hotmail.com >
} 
the need of tracing a profile of languages offered in the school curriculum of the public education system. The methodological procedures included a data survey through questionnaire in the fifteen cities that compose the region. From this survey, it was possible to recognize each city situation regarding the languages offered in schools and the latest local linguistic policies. The records' analysis shows small investment in the immigration languages still present in the micro-region, as well as the need to discuss the role of the school while facing contemporary multilingualism.

Keywords: Additional Language; Micro-region of Blumenau; Basic Education; Immigration Languages.

\section{INTRODUCุÃO}

No Brasil, há vários cenários interculturais que foram se constituindo e se transformando em diferentes momentos históricos e que precisam ser considerados na educação formal e na formação de professores, no âmbito da educação linguística. A região do Vale do Itajaí, no Estado de Santa Catarina, é um desses cenários, que se formou a partir de meados do século XIX, em decorrência da política de imigração adotada no país (SEYFERTH, 2002). Essa região, assim como outras zonas de imigração no Brasil, foi alvo de duas campanhas de nacionalização do ensino (a primeira a partir de 1911 e a segunda a partir de 1937) que tinham como propósito a imposição do uso de uma única língua, a língua oficial do País. No entanto, movimentos de resistência (FRITZEN; EWALD, 2013; KRIESER, 2015) por parte dos grupos de línguas minoritárias fizeram/fazem com que línguas de imigração, como o alemão e o italiano, ainda sejam faladas na região, adquiridas no âmbito familiar. A imposição do silenciamento linguístico provocou ressentimentos, marcou negativamente a trajetória de vida, como a experiência escolar, de vários falantes de línguas de imigração e precisa ser lembrada e problematizada como uma política de negação das diferenças e de reafirmação de um ideal monocultural.

Hoje, se buscarmos documentos oficiais relacionados à educação, é possível constatar a tendência atual de se produzirem discursos em prol da diversidade, pluralidade e respeito às diferentes culturas (BRASIL, 2008, 2010, 2014), o que pode ser considerado um avanço nos modos de conceber as diferenças culturais. No entanto, como observa Altenhofen (2013), esses documentos nacionais circulam mais no âmbito das secretarias e pastas que tratam da cultura e não propriamente no campo da educação. Nessa área, a discussão sobre a pluralidade linguística e, por consequência, as línguas minoritárias, nos contextos educacionais, não raro, carece de 
espaço e de reflexão. Como a escola tem lidado com a escolarização em contextos em que línguas de imigração, como línguas de herança, ainda estão presentes? Que estatuto essas línguas têm na escola em sociedades contemporâneas como as atuais, em que os conhecimentos de línguas internacionais de prestígio costumam ser valorizados, como um capital cultural, nos termos de Bourdieu (1996)? Como "O direito ao ensino da própria língua e da própria cultura", conforme apregoa a Declaração Universal dos Direitos Linguísticos ${ }^{1}$ (1996, p. 5), tem sido considerado na educação formal?

Essas preocupações motivam-nos a dar continuidade a pesquisas anteriores (FRITZEN, 2007; FRITZEN; EWALD, 2016; LORENZI; FRITZEN, 2017) nesse cenário cultural e sociolinguisticamente complexo (CAVALCANTI, 2011). Desse modo, no espaço deste artigo, pretendemos relatar uma pesquisa, inserida na área da Educação, em diálogo com o campo da Linguística Aplicada, que teve como objetivo geral mapear as políticas de educação linguística no tocante às línguas oferecidas no currículo escolar dos sistemas de ensino municipal e estadual na Microrregião de Blumenau, SC. Esse levantamento se torna necessário para, em primeiro lugar, (i) se conhecer a oferta de línguas adicionais nas escolas da região, (ii) compreender de que modo o setor público lida com leis que tratam da oferta de línguas nas escolas de educação básica, como a Lei de Diretrizes e Bases da Educação Nacional (LDBEN) nº 9.394/1996, a Lei no $11.161 / 2005$, para igualmente,(iii) ser possível prever e planejar a educação linguística na formação inicial e continuada de professores para atuarem na região. A pesquisa também pode fornecer subsídios para se compreender até que ponto os discursos em prol da diversidade, especialmente a diversidade linguística, no escopo da qual estão contidas as línguas minoritárias, encontram ressonância nas políticas de educação linguística numa região marcada pelo plurilinguismo.

Com o intuito de ampliar o debate em torno da "educação linguística" (CAVALCANTI, 2013), tendo em vista a relevância desse tema para a contemporaneidade, buscamos socializar dados parciais dessa pesquisa. Para atender a esse propósito, organizamos o texto da seguinte forma: inicialmente, após esta introdução, apresentamos o contexto histórico da Microrregião de Blumenau, filiando-nos especialmente a estudos teóricos que tratam do bi/plurilinguismo em contextos de línguas minoritárias; em seguida discorremos sobre a metodologia da investigação; na sequência, discutimos os registros da investigação em duas seções de análise. Na primeira, buscamos identificar que línguas adicionais ${ }^{2}$ são oferecidas e ensinadas nas 
escolas da Microrregião. $\mathrm{Na}$ segunda, procuramos discorrer sobre mudanças recentes nas políticas de educação linguística locais nos sistemas de ensino municipal e estadual da Microrregião. Por fim, apresentamos as considerações finais do estudo e as implicações da pesquisa para a área da educação linguística.

\section{CONTEXTO DA MICRORREGIÃO DE BLUMENAU}

A Microrregião de Blumenau, conforme mencionado anteriormente, situa-se no médio Vale do Itajaí, no Estado de Santa Catarina. A área tem influência predominante da colonização italiana e alemã (SEYFERTH, 1981), cujas manifestações culturais estão presentes ainda hoje nos municípios que fazem parte do Vale. Sobre os primeiros imigrantes "que se fixaram no Vale do Itajaí, em 1836, eram alemães egressos da colônia de São Pedro de Alcântara (fundada em 1829, pouco antes do corte de despesas que inviabilizou a colonização com imigrantes)" (SEYFERTH, 2011, p. 48). O Vale é formado pelos rios Itajaí-Açu e Itajaí-Mirim e seus afluentes, é composto pela união de 54 municípios e quatro microrregiões: Blumenau, Itajaí, Ituporanga e Rio do Sul.

O foco deste estudo, a Microrregião de Blumenau, está dividido hoje em 15 municípios, em uma área de 4.752,975 km² e população de 677.553 habitantes, segundo censo do IBGE de 2010. Historicamente, Blumenau foi fundado como uma colônia, em 1850, pelo alemão Hermann Otto Blumenau. "De todas as ex-colônias alemãs no Brasil, o município de Blumenau é, sem dúvidas, um dos que se destacaram mais por sua bem-sucedida economia e pela preservação de traços e valores alemães" (LUNA, 2000, p. 30).

Essas manifestações culturais estavam presentes na imprensa local em língua alemã, que teve um importante papel como veículo de expressão da etnicidade germânica e porta-voz dos interesses dos imigrantes e seus descendentes (SEYFERTH, 1999). Do mesmo modo, os jornais e a literatura na língua de imigração também promoveram a ampliação e valorização de "práticas de letramentos" (STREET, 2014), como diríamos hoje, em língua alemã. Nesse sentido, o amplo sistema de ensino, organizado pelos próprios grupos teuto-brasileiros, com escolas comunitárias e religiosas, também serviu para disseminar o aprendizado da escrita e a legitimação do espaço da língua alemã na escola.

Com a visibilidade do crescimento da colônia Blumenau, outros imigrantes também vieram para a região Sul do País, como cita Seyferth (2011, p. 50): 
Transformado em região de colonização oficial, o médio Vale do Itajaí passou a ser o destino de imigrantes alemães atraídos pelos subsídios, via agenciadores a serviço do governo imperial. Isso mudou o perfil do colono, pois, a partir de 1875 , começaram a chegar imigrantes de outras origens nacionais, notadamente italianos e poloneses.

Os imigrantes italianos que chegaram a então colônia Blumenau nessa época, a partir de 1875 , foram assentados numa região entre a confluência do rio dos Cedros e do rio Benedito e fundaram comunidades italianas no médio Vale do Itajaí, hoje municípios de Ascurra e Rodeio (SILVA, 1972).

Quanto ao sistema de ensino, apesar da precariedade das primeiras escolas, no início do século XX, os descendentes de imigrantes alemães que habitavam o Vale já haviam desenvolvido um sólido sistema de educação. Cerca de 40\% das escolas de Blumenau eram comunitárias ou religiosas (LUNA, 2000; MAILER, 2003).

Em 1904, o município de Blumenau compreendia uma área de $10.610 \mathrm{~km},{ }^{2}$ o que correspondia a 10\% do território do Estado, e possuía 35 mil habitantes. (ACIB, $\left.{ }^{4} 1989\right)$. A maioria dos municípios que compõem a Microrregião foco da pesquisa ora relatada faziam parte de Blumenau e foram emancipados no decorrer do século XX.

A Microrregião é composta atualmente pelos 15 seguintes municípios: ${ }^{5}$ Apiúna, colonizada a partir de 1878 por alemães, poloneses e italianos, com população de 9.683 habitantes; Ascurra, instituído pela Lei $\mathrm{n}^{\circ} 878$ de $1^{\circ}$. de abril de 1963, com 7.412 habitantes; Benedito Novo, fundado em 1880 como colônia de Blumenau, possui 10.336 habitantes; Blumenau, terceira cidade mais populosa do Estado, possui 309.011 mil habitantes; Botuverá, com população de 4.468 habitantes; Brusque, com 105.503 moradores; Doutor Pedrinho, que surgiu quando migrantes vindos das cidades vizinhas entre 1910 e 1920 mudaramse para suas terras, oficialmente feito município em janeiro de 1988, com 3.604 habitantes; Gaspar, com população de 57.981 habitantes; Guabiruba, com população de 18.430, emancipada de Brusque em 1962; Indaial, com população estimada em 54.854 habitantes, colonizada por volta de 1860 por alemães, em 1875 recebeu imigrantes italianos e em 1878, poloneses; Luiz Alves, fundada em 1877, com 10.438 habitantes; Pomerode, colonizada por imigrantes pomeranos em 1863, possui 27.759 habitantes; Rio dos Cedros, criado por uma família italiana da região de Trentino, com população de 10.284 habitantes; Rodeio, com população de 10.922 habitantes; por fim, Timbó, fundado por alemães vindos da Colônia Blumenau, mais tarde recebeu imigrantes italianos, com população de 36.744 habitantes. 
Com relação às políticas de educação linguística, podemos constatar movimentos recentes em prol do ensino de línguas de imigração na Microrregião. No ano de 2002, por exemplo, foi elaborado o Projeto de Política Linguística do Município de Blumenau, que tinha como propósitos a "valorização e o reconhecimento da língua alemã em Blumenau, como elemento estruturante da cultura e identidade de seus habitantes" (MAILER, 2003, p. 63). Dentro dessa política maior, foi elaborado o projeto intitulado "Escolas Bilíngues", que ofereceria o ensino de alemão ao lado da língua portuguesa em escolas rurais do município, situadas em contextos nos quais a língua de imigração ainda está presente na oralidade. Com mudanças ocorridas na administração municipal, no ano de 2005, o projeto, que nunca chegou a ser efetivado, foi suspenso, restando apenas duas aulas obrigatórias de alemão no currículo dessas escolas do campo do município (FRITZEN, 2012).

Já no município de Pomerode, cidade vizinha de Blumenau, a língua alemã é disciplina curricular do sistema municipal a partir do primeiro ano do ensino fundamental. Além disso, duas escolas oferecem educação bilíngue a partir do primeiro ano escolar desde 2008 (SPIESS, 2014). Com relação ao italiano, outra língua brasileira de imigração ainda presente no Vale, já fazia parte do sistema de ensino na cidade de Rodeio desde 2001, embora tenha sido retirada a partir do ano de 2014 do currículo das escolas estaduais, permanecendo apenas nas municipais (LORENZI, 2014).

Nas escolas em que se oferece uma língua adicional, ainda presente na comunidade, nem sempre são considerados os conhecimentos prévios dos alunos relativos ao seu repertório linguístico, conforme pesquisas anteriores já sinalizaram (FRITZEN, 2007, 2011, 2012; FRITZEN; RISTAU, 2013). Constata-se, assim, a falta de dados, ou seja, de conhecimentos sobre a oferta de línguas adicionais nas escolas da Microrregião de Blumenau, bem como a relação das línguas ensinadas na escola com as línguas de herança da comunidade. Neste artigo, porém, enfatizamos apenas a oferta de línguas no currículo das escolas, uma vez que foi esse o foco da pesquisa em questão. Reconhece-se, porém, a necessidade de se dar continuidade às pesquisas nessa área.

\section{PROCEDIMENTOS METODOLÓGICOS}

$\mathrm{Na}$ pesquisa ora relatada, de cunho qualitativo, mas que também gerou dados quantitativos, foi utilizado como instrumento um questionário, contendo perguntas abertas (com respostas discursivas) 
e fechadas (com perguntas de múltipla escolha), organizado em duas seções. A primeira seção focou o sistema de ensino de cada município (unidades escolares e informações sobre as línguas presentes no currículo) e a segunda, os documentos referentes ao ensino de línguas. O referido instrumento (vide anexo) foi aplicado às secretarias municipais e Gerências Regionais de Educação (GERED) dos municípios da Microrregião de Blumenau.

Inicialmente, foi feito contato telefônico com as secretarias de educação dos 15 municípios da Microrregião de Blumenau e das três GERED estabelecidas nessa região a fim de explicar o projeto e convidálas a participarem do estudo. Após o consentimento de colaboração dos gestores, o questionário, bem como o Termo de Consentimento Livre e Esclarecido (TCLE), foram enviados via e-mail no primeiro semestre de 2014 aos municípios e Gerências. Das 15 secretarias préselecionadas, responderam ao instrumento 13 secretarias, dos seguintes municípios: Timbó, Brusque, Blumenau, Rodeio, Rio dos Cedros, Pomerode, Indaial, Guabiruba, Gaspar, Ascurra, Doutor Pedrinho, Luís Alves e Botuverá. Com relação às Gerências, todas as três GERED (Timbó, Brusque e Blumenau) responderam ao instrumento.

\section{LÍNGUAS ADICIONAIS NA EDUCAC̦ÃO BÁSICA}

Nesta seção, buscamos discutir os dados gerados por meio dos questionários aplicados às 13 Secretarias e às três GERED dos municípios da Microrregião de Blumenau, relacionando-os com os aportes teóricos aos quais nos filiamos, isto é, o diálogo entre a Educação e a Linguística Aplicada, bem como com documentos oficiais relativos ao ensino de línguas na educação básica.

Primeiramente, analisamos as perguntas do questionário aplicado às secretarias municipais e GERED que se referiam aos dados relativos à quantidade de escolas, às línguas oferecidas no currículo, carga horária, entre outros aspectos. Em seguida, discorremos a respeito da segunda seção do instrumento, relativa aos documentos referentes ao ensino de línguas.

\subsection{SOBRE AS LÍNGUAS ADICIONAIS OFERTADAS NAS ESCOLAS E CENTROS DE EDUCAÇ̃̃O INFANTIL}

Quanto à oferta de línguas adicionais nas escolas, as três GERED oferecem a disciplina no currículo para o ensino médio e fundamental $^{7}$ e 12 secretarias municipais de educação ofertam para o 
ensino fundamental, ${ }^{8}$ conforme prevê a Lei de Diretrizes e Bases da Educação Nacional, LDBEN n ${ }^{\circ} 9.394 / 96$, em seu art. $26^{\circ}$, parágrafo $5^{\circ}$ :

Na parte diversificada do currículo será incluído, obrigatoriamente, a partir da quinta série, o ensino de pelo menos uma língua estrangeira moderna, ${ }^{9}$ cuja escolha ficará a cargo da comunidade escolar, dentro das possibilidades da instituição (BRASIL, 2015, p.16).

As Diretrizes Curriculares Nacionais para a Educação Básica, Resolução n. 4, de 13 de julho de 2010, (BRASIL, 2010), fazem menção a esse artigo da LDBEN e reforçam a necessidade de se incluir no currículo pelo menos uma "língua estrangeira moderna". Quanto a sua escolha, as Diretrizes confirmam o papel da comunidade escolar nesse sentido e acrescentam: [...] dentro das possibilidades da escola, que deve considerar o atendimento das características locais, regionais, nacionais e transnacionais, tendo em vista as demandas do mundo do trabalho e da internacionalização de toda ordem de relações. (BRASIL, 2010, p. 6). O documento sinaliza o reconhecimento da diversidade cultural no contexto onde as escolas estão inseridas e aponta para sua relação com o contexto global mais amplo, incluindo questões de trabalho e internacionalização, discussão bastante presente na esfera do ensino superior. Nesse caso, podemos inferir que as línguas de imigração, como línguas europeias, poderiam ter um papel importante nesse aspecto.

Para melhor visualização dos dados e posterior análise, no quadro abaixo, é discriminada a quantidade de escolas que compõe cada GERED e secretaria de educação dos municípios que participaram da pesquisa, além dos idiomas que elas oferecem no currículo.

QUADRO 1. Dados das GERED e Secretarias Municipais sobre as línguas adicionais e as escolas

\begin{tabular}{|c|c|c|c|}
\hline Município & $\begin{array}{l}\text { Quantidade de } \\
\text { escolas por } \\
\text { Secretaria/ } \\
\text { GERED }\end{array}$ & $\begin{array}{c}\text { Quantidade } \\
\text { de escolas } \\
\text { que oferecem } \\
\text { apenas } \\
\text { uma língua } \\
\text { adicional }\end{array}$ & $\begin{array}{l}\text { Quantidade de } \\
\text { escolas que } \\
\text { oferecem duas } \\
\text { ou mais línguas } \\
\text { opcionais }\end{array}$ \\
\hline 35a GERED de Timbó & 23 & $\begin{array}{l}11 \text { - Espanhol } \\
11 \text { - Inglês }\end{array}$ & $\begin{array}{l}1 \text { - Espanhol e } \\
\text { Alemão }\end{array}$ \\
\hline $16^{\mathrm{a}}$ GERED de Brusque & 27 & 25 - Inglês & $\begin{array}{l}2 \text { - Português e } \\
\text { Guarani }\end{array}$ \\
\hline $15^{\mathrm{a}}$ GERED de Blumenau & 47 & 46 - Inglês & $\begin{array}{l}1 \text { - Não informou } \\
\text { que língua além } \\
\text { de Inglês }\end{array}$ \\
\hline
\end{tabular}


9

\begin{tabular}{|c|c|c|c|}
\hline Secretaria de Timbó & 6 & Nenhuma & $\begin{array}{l}6 \text { - Inglês } \\
\text { e Espanhol }\end{array}$ \\
\hline Secretaria de Rodeio & 5 & Nenhuma & $\begin{array}{l}5 \text { - Inglês } \\
\text { e Italiano }\end{array}$ \\
\hline Secretaria de Rio dos Cedros & 2 & 2 - Inglês & Nenhuma \\
\hline Secretaria de Pomerode & 12 & $\begin{array}{l}3 \text { - Alemão } \\
1 \text { - Inglês }\end{array}$ & $\begin{array}{l}8 \text { - Inglês } \\
\text { e Alemão }\end{array}$ \\
\hline Secretaria de Indaial & 13 & 13 - Inglês & Nenhuma \\
\hline Secretaria de Guabiruba & 11 & 9 - Inglês & $\begin{array}{l}2 \text { - Inglês } \\
\text { e Alemão }\end{array}$ \\
\hline Secretaria de Gaspar & 15 & 15 - Inglês & Nenhuma \\
\hline Secretaria de Brusque & 26 & 22 - Inglês & $\begin{array}{l}4 \text { - Espanhol } \\
\text { e Italiano }\end{array}$ \\
\hline Secretaria de Ascurra & 5 & 5 - Inglês & Nenhuma \\
\hline Secretaria de Blumenau & 50 & $\begin{array}{l}32 \text { - (07 Alemão } \\
\text { e } 25 \text { Inglês })^{10}\end{array}$ & $\begin{array}{l}13 \text { - Inglês } \\
\text { e Alemão }\end{array}$ \\
\hline Secretaria de Doutor Pedrinho & 1 & 1 - Inglês & Nenhuma \\
\hline Secretaria de Luís Alves & 5 & 5 - Inglês & Nenhuma \\
\hline TOTAL DE ESCOLAS & 248 & 201 & 42 \\
\hline
\end{tabular}

Fonte: Elaborado pelas pesquisadoras.

Conforme mostram os dados do Quadro 1, as escolas que possuem ensino fundamental e/ou médio ofertam alguma língua adicional no currículo. A maioria das escolas (201/81\%) oferece apenas uma língua adicional, ao passo que 17\% (42) oferecem duas línguas adicionais. Entre as línguas adicionais, aparecem inglês, espanhol, alemão, italiano e guarani. Em todas as GERED e Secretarias, o inglês é oferecido ou como única língua adicional do currículo, ou ao lado de outra língua. Entre as línguas adicionais referentes às línguas de imigração, o idioma alemão faz parte do currículo de 34 escolas da Microrregião de Blumenau, isto é, está presente em 12,9\% das escolas, do total de 248. Já a língua italiana faz parte do currículo de nove 
escolas, isto é, de 3,6\% das escolas da Microrregião. O espanhol, como língua adicional, é ofertado em 26 escolas da Microrregião, ou seja, em $10,48 \%$ do total das escolas. Registra-se ainda a presença de uma língua indígena, o guarani, em duas escolas da GERED de Brusque. ${ }^{11}$

A justificativa social para a inclusão de uma língua no currículo, de acordo com os Parâmetros Curriculares Nacionais para o Ensino Fundamental - PCN (BRASIL, 1998), "deve ser determinada, entre outros fatores, pela função que desempenha na sociedade. Em relação a uma língua estrangeira, isso requer uma reflexão sobre o seu uso efetivo pela população" (BRASIL, 1998, p. 20).

Os PCN do ensino médio, por sua vez, mencionam que

As Línguas Estrangeiras assumem a condição de serem parte indissolúvel do conjunto de conhecimentos essenciais que permitem ao estudante aproximar-se de várias culturas e, consequentemente, propiciam sua integração num mundo globalizado. (BRASIL, 2000).

A perspectiva desses documentos oficiais de parametrização justifica o ensino de línguas adicionais pelo viés cultural e seus usos efetivos nas sociedades contemporâneas, o que favoreceria a compreensão do próprio contexto social em que o/a aluno/a está inserido/a. De acordo com o que já foi discutido neste artigo, no contexto histórico da pesquisa, a Microrregião de Blumenau foi colonizada por imigrantes europeus e, atualmente, ainda há influência dos colonizadores nos municípios, principalmente no tocante à presença das línguas de imigração. Conforme pesquisas anteriores (FRITZEN, 2012; FRITZEN; EWALD, 2013, 2016), há um número significativo de falantes de diferentes línguas de imigração na região, tendo assim o seu uso efetivo pela população.

Se levarmos em conta a presença dessas línguas de imigração no cenário pesquisado, certamente esse seria um argumento indiscutível na oferta dessas línguas nas escolas. No entanto, como afirma Altenhofen (2013, p. 95, grifos do autor),

[...] toda e qualquer língua, seja ela minoritária ou majoritária, possui uma importância e um valor no 'mercado linguístico' que dependem de uma série de fatores. É uma ilusão pensar que as línguas são iguais, no sentido do que são capazes, mas todas - sem exceção - têm o seu valor definido pelos usuários e respectivas comunidades de fala, a quem deve ser garantido o direito de uso. Esse valor de mercado, assim como o status sócio-político de uma língua variam conforme o contexto de uso e o ponto de vista que se adota.

Na história do Vale do Itajaí, as línguas de imigração estiveram marcadas por diferentes formas de conflito com o português e 
demais línguas presentes neste cenário. Antes do período das políticas linguísticas nacionalizadoras do governo getulista (1937-1945), o idioma alemão desfrutava de valor social no "mercado linguístico", uma vez que era ensinado nas escolas, ${ }^{12}$ bem como tinha grande circulação na imprensa, na literatura e em outras esferas. De língua de prestígio, presente em "práticas de letramentos" (STREET, 2014) valorizadas socialmente, passou à língua estigmatizada, associada em geral à língua de colono (FRITZEN, 2012). Essa mudança de status se deve a um longo processo em que as escolas serviram de instrumento a favor da disseminação de um ideal monocultural e monolíngue e, durante muito tempo, desconsideraram a presença de outras línguas, além do português, nos contextos sociais em que elas se inseriam. Ainda hoje, nem sempre as línguas de herança/ imigração são consideradas no contexto escolar e/ou, não raro, os conhecimentos linguísticos prévios dos alunos/as são vistos como problema para o aprendizado da modalidade escrita do português (CAVALCANTI, 2011; FRITZEN, 2011).

Embora a Proposta Curricular de Santa Catarina (1998) tenha feito uma modificação na política de ensino de língua estrangeira, "migrando de uma posição monolinguística, [...] para uma posição plurilinguística, até hoje o ensino de língua inglesa predomina nas escolas da rede pública" (SILVEIRA, 2011, p. 104). A Proposta Curricular de Santa Catarina mais recente postula que

Estudar uma língua estrangeira/adicional é oportunidade de conhecer outra cultura por meio da língua, de modo a ampliar o repertório de conhecimentos que envolve não somente o idioma, mas aspectos mais amplos, modos de vida dos falantes da língua em estudo. (SANTA CATARINA, 2014, p. 124).

Em Blumenau, apesar de iniciativas com o intuito de reintegrar a língua alemã ao currículo das escolas a partir da década de 1980, o alemão foi perdendo espaço no ensino, já que "a grade curricular do ensino fundamental privilegia o inglês em detrimento das outras línguas" (MAILER, 2003, p. 50). Embora haja escolas do campo que passaram a oferecer a língua alemã na educação infantil e nos primeiros anos do ensino fundamental, a partir de 2005, ainda hoje se pode constatar, de acordo com o quadro anterior, a predominância do inglês como língua adicional.

Das secretarias que oferecem somente a língua inglesa no currículo escolar, Rio dos Cedros, Indaial, Gaspar, Ascurra, Doutor Pedrinho e Luís Alves possuem a influência das culturas alemã, italiana e polonesa, bem como falantes dessas línguas de herança na região. Sobre a oferta da língua alemã no ensino médio, apenas a 
GERED da cidade de Timbó informou oferecer o idioma alemão em uma escola. Já as secretarias municipais que assinalaram ofertar a língua alemã no currículo para o ensino fundamental, que também possuem a influência dessa cultura, foram as cidades de Pomerode, Guabiruba e Blumenau, embora mais da metade das escolas de Blumenau ofereçam somente inglês.

Os PCN (1998, p. 15) consideram três fatores para a inclusão de uma língua estrangeira no currículo: "fatores relativos à história, às comunidades locais e à tradição". Sobre o segundo fator, o documento ainda salienta que "a convivência entre comunidades locais e imigrantes ou indígenas pode ser um critério para a inclusão de determinada língua no currículo escolar" (BRASIL, 1998, p. 23). A LDBEN no 9.394, conforme mencionada anteriormente, determina, no seu art. $26^{\circ}$, que os currículos da educação básica sejam complementados com uma parte diversificada "[...] exigida pelas características regionais e locais da sociedade, da cultura, da economia e dos educandos" (BRASIL, 2015, p. 19, grifo nosso). Ainda no mesmo artigo, acrescenta-se que a "[...] escolha ficará a cargo da comunidade escolar, dentro das possibilidades da instituição" (BRASIL, 2015, p.20).

Esses dois documentos oficiais nacionais fazem menção a comunidades locais, a características regionais, a grupos de imigrantes e indígenas, que deveriam ser considerados na composição do currículo da educação básica. Se compreendermos a língua e a cultura não como constructos abstratos e permanentes, mas a língua como uma dimensão da cultura (MAHER, 2007), entenderemos a relação indissociável entre esses dois conceitos e o aspecto sócio-histórico e processual que os envolvem (STREET, 2014; MAHER, 2007). Nesse sentido, podemos inferir que tanto o documento de parametrização quanto a LDBEN abrem possibilidades para a educação romper com a lógica de homogeneização cultural. Ambos os textos apontam para a necessidade de se olhar o entorno e, nesse sentido, podemos acrescentar, reconhecendo os "saberes locais" (CANAGARAJAH, 2004). Esse olhar sensível poderia resultar em ações concretas na escola em prol da ampliação do repertório linguístico dos diferentes grupos sociais, tendo como perspectiva a "educação para a interculturalidade" (MAHER, 2007) e as línguas como patrimônios culturais imateriais.

No entanto, os dados parecem apontar para uma tímida tomada de posição dos sistemas de ensino no contexto pesquisado nessa direção. Ainda há um número reduzido de escolas que têm investido na oferta de mais de uma língua adicional além do inglês. Em alguns 
casos, como o do município de Rodeio, a língua italiana foi substituída pelo espanhol. Essa questão voltará à discussão na próxima seção.

No que diz respeito às respostas das instituições sobre o ano em que a(s) língua(s) adicional(is) passou(ram) a compor o currículo escolar, as respostas variaram entre os anos de 1981 a 2008. A 35 GERED de Timbó respondeu que "Desde 2008 (espanhol). Alemão, antes ainda. Inglês faz parte das disciplinas". A Secretaria de Gaspar respondeu que a mudança ocorreu "com efetivação de profissionais desde 1998" e a cidade de Luís Alves informou que "Para os Anos Finais, o idioma inglês é oferecido desde quando a Educação municipal seguia o sistema de Ensino Estadual. Com o sistema Municipal de Ensino, desde o ano de 2002 (Lei 1045/2002). A partir de 2011, o idioma também é oferecido desde $03^{\circ}$ ano do Ensino Fundamental'. ${ }^{13}$

Com relação ao modo de oferta da língua, todas as gerências e secretarias municipais assinalaram a opção do período normal de aulas. Somente a Secretaria Municipal de Brusque informou oferecer também no contraturno, desde o ano de 2004.

Sobre os centros ou unidades de educação infantil, apenas cinco secretarias oferecem uma língua adicional, uma vez que a educação infantil possui uma proposta curricular diferente. A Secretaria Municipal de Rio dos Cedros oferece inglês em dois centros, mas não informou o ano em que essa prática iniciou. O município de Ascurra oferta a língua inglesa para uma unidade desde 2004. Já em Pomerode dois centros de educação infantil bilíngues ofertam a língua alemã. Sobre essa oferta, Spiess (2014, p. 15) afirma:

O projeto bilíngue, implementado em 2008/2009 em duas escolas públicas do município de Pomerode, surgiu como uma iniciativa de considerar a pluralidade linguística da região. O projeto consiste em oferecer aulas em alemão e em português, a partir da Educação Infantil, continuando nos anos seguintes que compõem o Ensino Fundamental.

$\mathrm{Na}$ cidade de Blumenau, de acordo com os dados, somente uma unidade de educação infantil oferece a língua alemã desde 2004. ${ }^{14}$ A Secretaria Municipal de Timbó assinalou que 13 unidades pré-escolares oferecem um idioma além do português desde 2002, mas sem informar qual. Sobre a forma como as aulas são oferecidas, todos assinalaram que elas acontecem no período comum de aulas.

Todos esses dados sinalizam que as secretarias e gerências atendem minimamente à LDBEN no 9394/1996, no sentido de oferecer pelo menos uma língua adicional. Constata-se também o lugar privilegiado que a língua inglesa ocupa nas escolas da Microrregião. Não 
há dúvidas de que o currículo da educação básica deveria contemplar o ensino dessa língua, pela importância e status que tem hoje no contexto global das sociedades contemporâneas. No entanto, um olhar mais atento aos contextos locais poderia revelar o potencial linguístico presente em muitas comunidades, nas quais ainda circulam línguas de imigração. Já há iniciativas mais recentes de políticas linguísticas que transformam línguas minoritárias, como o alemão, o italiano, em línguas do currículo, mas ainda não suficientes para garantir uma pedagogia do plurilinguismo, que considerasse a diversidade linguística local e global.

\subsection{SOBRE OS DOCUMENTOS REFERENTES AO ENSINO DE LÍNGUAS}

Uma das perguntas do questionário estava relacionada às leis, resoluções ou documentos que regulamentam/vam a oferta do ensino de línguas no município. Duas GERED e cinco secretarias municipais não responderam. As secretarias que informaram a existência de documentos referentes ao ensino de línguas adicionais são as seguintes:

1) Secretaria de Educação de Rodeio: ata do Conselho Municipal de Educação de 30/03/2009; emenda na Lei Orgânica; línguas adicionais: italiano e inglês;

2) Secretaria de Educação de Timbó: novas Diretrizes Curriculares (2007); línguas adicionais: espanhol e inglês;

3) Secretaria de Educação de Guabiruba: nova Política Linguística (2013); línguas adicionais: alemão e inglês;

4) Secretaria de Educação de Blumenau: novas Diretrizes Curriculares (2012); ${ }^{15}$ línguas adicionais: alemão e inglês.

Sobre os documentos existentes, a GERED de Timbó informou que "Na rede pública Estadual de acordo com a lei no 11.161/2005 a Lingua Espanhola é de oferta obrigatória pela escola no Ensino Médio, com matrícula facultativa do aluno".

Sobre a língua espanhola, mencionada pela Secretaria de Timbó, é importante ressaltar que a referida Lei n ${ }^{\circ} 11.161 / 2005$, em seu art. $1^{\circ}$, prescreve: "O ensino da língua espanhola, de oferta obrigatória pela escola e de matrícula facultativa para o aluno, será implantado, gradativamente, nos currículos plenos do ensino médio”. Sobre essa questão, a pesquisa de Teran (2012) mostra a situação das escolas na cidade de Blumenau:

Na região da $15^{\mathrm{a}}$ Gered observamos que a primeira disciplina LE moderna escolhida na maioria das instituições educativas tem sido LE Inglês e na maioria 
das escolas pesquisadas a segunda opção tem sido LE Espanhol, mesmo não acompanhando a história cultural da região e apenas se sujeitando à lei 11.161/2005 e não à realidade do contexto histórico-cultural local. (TERAN, 2012, p. 45).

O que outras pesquisas também têm mostrado (videLORENZI, 2014) é que leis e documentos oficiais referentes ao ensino de línguas adicionais são reinterpretados e ressignificados no âmbito da gestão estadual, municipal e em cada unidade escolar. A referida Lei $\mathrm{n}^{\circ}$ 11.161, por exemplo, já serviu de argumento para a exclusão de uma língua de imigração em um dos municípios da Microrregião. Esse fato sinaliza que a inclusão ou exclusão de uma língua do currículo pode ter como causa fatores políticos complexos, nem sempre claramente explicitados. As atitudes linguísticas (CALVET, 2002) dos falantes com relação às diferentes línguas também se relacionam ao valor que as línguas desfrutam no "mercado linguístico".

Ainda com relação à pergunta sobre documentos relativos a políticas linguísticas municipais, a Secretaria Municipal de Rodeio informou, conforme mencionado anteriormente, que "Foi documentado em Ata de Reunião do Conselho Municipal de Educação em 30/03/2009, onde a Lingua Italiana passou a fazer parte da Grade Curricular, com carga horária semanal de 1 aula por turma de $1^{a}$ a $8^{a}$ série na época, hoje o Ensino Fundamental de $9^{\circ}$ Anos. E passou a constar na Lei Orgânica do Município por emenda."

Lorenzi (2014, p. 54) relata em sua pesquisa que

Em 2005, a Lei Municipal no 1504, de 26 de outubro [...] cria cargos de provimento efetivo, também, para professores com formação em Língua Italiana. Assim, todos os estudantes matriculados nas escolas municipais rodeenses de Ensino Fundamental têm, hoje, uma aula semanal obrigatória de língua italiana com um profissional habilitado e efetivo.

Sobre a última mudança que ocorreu em relação ao ensino de línguas, as três GERED não responderam à pergunta. Já a Secretaria Municipal de Rodeio respondeu que "Foram redigidas novas diretrizes curriculares. Tem objetivo de preservar a Cultura do Município de origem italiana. Oferecemos a Lingua Inglesa do $1^{\circ}$ ao $9^{\circ}$ ano do E. F. por determinação do MEC." As escolas municipais oferecem uma aula por semana de Inglês e uma de Italiano do primeiro ao nono ano.

Outras mudanças ocorreram recentemente em dois municípios da Microrregião. Em Timbó, "Foram redigidas novas diretrizes curriculares em 2007’, de acordo com o que foi citado anteriormente. Em Guabiruba, também mencionado acima, "Foi implementada nova política linguística em 2013. Por causa da Lingua alemã (devido à colonização alemã)". Segundo os dados do questionário sobre as escolas, o sistema municipal de ensino 
de Guabiruba oferta inglês e alemão em duas escolas. As aulas têm duração de 45 minutos e ocorrem no período normal de aulas.

Dentre essas três mudanças no estabelecimento de políticas de educação linguística na Microrregião de Blumenau, podemos constatar que duas caminham no sentido de ampliar a oferta de línguas adicionais no currículo, considerando o contexto local (Rodeio e Guabiruba). O município de Timbó parece caminhar em outra direção. De acordo com o Quadro 1 apresentado anteriormente, as seis escolas do sistema municipal de ensino oferecem como línguas adicionais Inglês e Espanhol. Não há, portanto, a oferta de línguas de imigração. Conforme Teran (2012) verificou no município de Blumenau, a Lei $n^{\circ}$ 11.161 determina a oferta da disciplina de Espanhol nas escolas, mas não prevê a obrigatoriedade de o aluno cursá-la. Nem sempre, porém, essa questão é considerada. A abertura que os documentos oficiais e a LDBEN proporcionam, em termos da oferta de línguas adicionais, não parece ser vislumbrada por muitos gestores, que acabam por negligenciar os saberes locais. Como afirma Altenhofen (2013, p. 104), "a história está repleta de exemplos de políticas de omissão ou indiferença". Não existe mais a proibição explícita das línguas de imigração, tratadas durante as campanhas de nacionalização como línguas estrangeiras, mas permaneceu, em muitos casos, a indiferença com relação à diversidade cultural em que as escolas se inserem.

\section{CONSIDERACִÕES FINAIS}

A partir da geração e análise dos dados discutidos neste artigo, podemos constatar que, embora todas as escolas ofereçam uma língua adicional, a maioria ainda oferta somente a língua inglesa no currículo, sugerindo, assim, o pouco investimento nas línguas de imigração ainda presentes na Microrregião de Blumenau. Verificamos que, das 13 secretarias que responderam ao questionário, somente cinco oferecem alguma língua de imigração: italiano ou alemão. Nessa perspectiva, a escola poderia ter uma grande parcela de contribuição para a manutenção dessas línguas de imigração, uma vez que ainda há crianças/jovens que adquirem a língua em casa, na modalidade oral, ou que têm contato com ela no âmbito familiar. Nesse sentido, seria necessário discutir o papel da escola diante desse plurilinguismo. A escola, depois de um longo período em que desconsiderou o cenário intercultural da Microrregião, deveria assumir seu papel na manutenção das línguas de herança presentes na região e na ampliação do repertório linguístico dos alunos da educação básica. Em tempos de grande ênfase 
às vantagens do bi/plurilinguismo, com vistas à "formação da cidadania ativa ou engajada" e à "inclusão social em sentido amplo" (MONTE MÓR, 2013, p. 231), as políticas de educação linguística deveriam considerar as potencialidades advindas das interações interculturais, e as relações entre as experiências locais e as práticas globais.

Esperamos que os resultados da presente pesquisa possibilitem o aprofundamento do debate sobre convergências e divergências entre políticas nacionais e locais, bem como suas interpretações nos municípios que compõem a Microrregião e em outros contextos similares de línguas minoritárias. Além desse aspecto, esperamos que os resultados possam oferecer subsídios importantes para a problematização do cenário sociolinguisticamente complexo de muitas regiões brasileiras, com vistas à formação inicial e contínua de um professor sensível à "diversidade e pluralidade cultural, social e linguística”, como nos ensina Cavalcanti (2013, p. 212).

\section{REFERÊNCIAS}

ALTENHOFEN, C. Bases para uma política linguística das línguas minoritárias no Brasil. In: NICOLAIDES, C; SILVA, K. A.; TILIO, R.; ROCHA, C. H. (org.) Política e políticas linguísticas. Campinas: Pontes Editores, p. 93-116, 2013.

ACIB 90 anos de memória. Blumenau: Fundação “Casa Dr. Blumenau”, 1989.

BOURDIEU, P. A economia das trocas linguísticas: o que falar quer dizer. São Paulo: EDUSP, 1996.

BRASIL. Secretaria de Educação Fundamental. Parâmetros curriculares nacionais: terceiro e quarto ciclos do ensino fundamental: língua estrangeira/Secretaria de Educação Fundamental. Brasília: MEC/SEF, 1998.

BRASIL. Secretaria de Educação Fundamental. Parâmetros curriculares nacionais: ensino médio / Secretaria de Educação. Brasília: MEC/SEF, 2000. Disponível em: < http:// portal.mec.gov.br/seb/arquivos/pdf/blegais.pdf>. Acesso em: 22 fev. 2016.

BRASIL. Orientações Curriculares Nacionais para o Ensino Médio. Brasília, D.F: Ministério da Educação, Secretaria de Educação Básica, 2008.

BRASIL. Diretrizes Curriculares Nacionais para a Educação Básica. Ministério da Educação. Conselho Nacional da Educação. Brasília: MEC, 2010.

BRASIL. Lei de Diretrizes e Bases da Educação Nacional. Lei número 9394, 20 de dezembro de 1996. $11^{\text {a }}$ ed., 2015.

BRASIL. Lei $\mathbf{n}^{\mathbf{o}}$. 11.161, de 05 de agosto de 2005. Disponível em:<http:/ /www.planalto.gov. br/ccivil_03/_Ato2004-2006/2005/Lei/L11161.htm>. Acesso em: 22 fev. 2016.

BRASIL. Plano Nacional de Educação 2014-2024. Lei no 13.005, de 25 de junho de 2014, que aprova o Plano Nacional de Educação (PNE) e dá outras providências. Brasília: Câmara 
dos Deputados, Edições Câmara, 2014. Disponível em:<http://www.observatoriodopne. org.br/uploads/reference/file/439/documento-referencia.pdf>. Acessoem:11ago. 2017.

CANAGARAJAH, A. S. Subversive identities, pedagogical safe houses, and critical learning. In: NORTON, B.; TOOHEY, K. (org.) Critical pedagogies and language learning. Cambridge: Cambridge University Press, p. 116-136, 2004.

CALVET, L.-J. Sociolinguística: uma introdução crítica. Tradução de Marcos Marcionilo. São Paulo: Parábola, 2002.

CAVALCANTI, M. C. Bi/multilinguismo, escolarização e o (re)conhecimento de contextos minoritários, minoritarizados e invisibilizados. In: MAGALHÃES, M. C. C.; FIDALGO, S. S.; SHIMOURA, A. S. (org.) A formação no contexto escolar: uma perspectiva críticocolaborativa. Campinas, SP: Mercado de Letras, p. 171-185, 2011.

CAVALCANTI, M. C. Educação linguística na formação dos professores de línguas: intercompreensão e práticas translíngues. In: MOITA LOPES, L. P. (org.) Linguística Aplicada na modernidade recente. São Paulo: Parábola,p. 211-226, 2013.

FRITZEN, M. P. “Ichkannmein Namemit letra junta und letra solta schreiben”: bilinguismo e letramento em uma escola rural localizada em zona de imigração alemã no Sul do Brasil. 2007. 305 f. Tese (Doutorado em Linguística Aplicada). Instituto de Estudos da Linguagem, Universidade Estadual de Campinas, Campinas, 2007.

FRITZEN, M. P. Reflexões sobre práticas de letramento em contexto escolar de lingual minoritária. D. E. L. T. A., São Paulo, v. 63, n. 76, p. 63-76, 2011.

FRITZEN, M. P. "Iana escola alemã e de um dia pro outro fechou. E nós não sabíamos falar o português”: refletindo sobre as políticas linguísticas em contexto de lingual minoritária. Linguagem \& Ensino, Pelotas, v.15, n.1, p. 113-138, jan./jul. 2012.

FRITZEN, M. P.; RISTAU, J. "Muitas coisas eles falam errado porque tem essa mistura da lingual alemã": vozes de professores sobre a Educação em contextos de línguas de imigração. Fórum Linguístico, Florianópolis, v. 10, n. 4, p. 259-270, out./dez. 2013.

FRITZEN, M. P.; EWALD, L. "Aqui somos protegidos pelas nossas quatro paredes. Aqui nós falamos alemão": histórias de letramentos interculturais no Vale do Itajaí, SC. Trabalhos em Linguística Aplicada, Campinas, v. 52, n. 2, p. 239-258, jul./dez. 2013.

FRITZEN, M. P.; EWALD, L. Reflexões sobre Políticas de Educação Linguística em Contexto Plurilíngue. Educação \& Realidade, Porto Alegre, v. 41, n. 2, p.491-512, jun. 2016.

KRIESER, D. S. 'São nossas raízes, é mais uma língua nossa, a língua mãe’: representações sobre a língua italiana em um contexto intercultural. 2015. 109 f, il. Dissertação (Mestrado em Educação) - Programa de Pós-Graduação em Educação, Centro de Ciências da Educação, Universidade Regional de Blumenau, Blumenau 2015. Disponível em: <http://www.bc.furb.br/docs/DS/2015/359674_1_1.pdf>. Acesso em: 11 ago. 2017.

KREUTZ, L. Língua de referência na escola teuto-brasileira: as tensões entre o uso do alemão e do português. In: CUNHA, J. L.; GÄRTNER, A. Imigração alemã no Rio Grande do Sul: história, linguagem, educação. Santa Maria, RS: EUFSM, p. 133-157, 2003.

LORENZI, E. M. B. Políticas linguísticas para o ensino de línguas em um cenário de imigração italiana no Vale do Itajaí, SC. Blumenau: FURB, 2014. 102 f, il. Dissertação (Mestrado em Educação) - Programa de Pós-Graduação em Educação, Centro de Ciências da 
Educação, Universidade Regional de Blumenau, Blumenau, 2014. Disponível em: < http:// www.bc.furb.br/docs/DS/2014/357691_1_1.pdf>. Acesso em: 11 ago. 2017.

LORENZI, E. M. B.; FRITZEN, M. P. Política linguística para o ensino do italiano em contexto de imigração. Revista Línguas \& Letras, Cascavel, v. 18, n. 41, p. 79-94, dez. 2017.

LUNA, J. M. F. O Português na Escola Alemã de Blumenau: da formação à extinção de uma prática. Itajaí: Ed. da Univali e Ed. da Furb, 2000.

MAHER, T. M. Do casulo ao movimento: a suspensão das certezas na educação bilíngue e intercultural. In: CAVALCANTI, M.; BORTONI-RICARDO, S. M. (org.), 2007, Transculturalidade, linguagem e educação. Campinas, SP: Mercado de Letras, p. 67-94, 2007.

MAILER, V. C. O. O alemão em Blumenau: uma questão de identidade e cidadania. Florianópolis, 2003. 95 f. Dissertação (Mestrado em Linguística) - Universidade Federal de Santa Catarina, Centro de Comunicação e Expressão. Programa de Pós-Graduação em Linguística.

MAAS, M. R.; FRITZEN, M. P.; AVELINO NETO, A. J. A língua alemã em antiga zona de imigração no vale do Itajaí (SC): um estudo em duas comunidades. Calidoscópio, São Leopoldo, v. 12, n. 2, p. 143-152, maio/ago. 2014.

MONTE MÓR, W. As políticas de ensino de línguas e o projeto de letramentos. In: NICOLAIDES, C; SILVA, K. A.; TILIO, R.; ROCHA, C. H. (org.) Política e políticas linguísticas. Campinas: Pontes Editores, p. 219-235, 2013.

NICCOLAIDES, C; TILIO, R. Políticas de ensino e aprendizagem de línguas adicionais. In: NICOLAIDES, C; SILVA, K. A.; TILIO, R.; ROCHA, C. H. (org.) Política e políticas linguísticas. Campinas: Pontes Editores, p. 285-305, 2013.

SANTA CATARINA. Secretaria de Estado da Educação e do Desporto. Proposta Curricular de Santa Catarina: Educação Infantil, Ensino Fundamental e Médio: Disciplinas Curriculares. Florianópolis: COGEN, 1998.

SANTA CATARINA. Governo do Estado. Secretaria de Estado da Educação. Proposta Curricular de Santa Catarina: Formação Integral na Educação Básica. 2014.

SEYFERTH, G. A dimensão cultural da imigração. Revista Brasileira Ciências Sociais, v. 26, n. 77, p. 47-62, 2011. Disponível em: <http://www.scielo.br/pdf/rbcsoc/v26n77/07. pdf> Acesso em: 11 ago. 2017.

SEYFERTH, G. Nacionalismo e identidade étnica. Florianópolis: Fundação Catarinense de Cultura, 1981.

SEYFERTH, G. A colonização alemã no Brasil: etnicidade e conflito. In: FAUSTO, B.(org.) Fazer a América. São Paulo: USP, p. 273-313, 1999.

SEYFERTH, G. Colonização, imigração e a questão racial no Brasil. Revista USP, São Paulo, n.53, p. 117-149, mar./maio 2002. Disponível em: <http://www.usp.br/revistausp/53/12giralda.pdf>. Acesso em: 09 jan. 2016.

SILVA, J. F. História de Blumenau. Florianópolis: Edeme, 1972.

SILVEIRA, A. P. K. Deslocamento de acento na aquisição da língua inglesa como segunda língua. Letras de Hoje, Porto Alegre, v. 46, n. 2, p. 104-112, abr./jun. 2011. Disponível em: <http://revistaseletronicas.pucrs.br/ojs/index.php/fale/article/ viewFile/7230/6576>. Acesso em: 11 ago. 2017. 
SPIESS, V. B. Discursos sobre ensino bilíngue em contexto intercultural: as vozes das famílias. Dissertação (Mestrado em Educação) - Programa de Pós-Graduação em Educação, Centro de Ciências da Educação, Universidade Regional de Blumenau, Blumenau, 2014. Disponível em: < http://www.bc.furb.br/docs/DS/2014/358742_1_1.pdf >. Acesso em: 11 ago. 2017.

STREET, B. Letramentos sociais: abordagens críticas do letramento no desenvolvimento, na etnografia e na educação. Trad.: Marcos Bagno. São Paulo: Parábola Editorial, 2014.

TERAN, A. T. L. A presença da disciplina língua estrangeira moderna espanhol no currículo escolar no Brasil: um estudo em escolas públicas da 15. GERED-SC. 2012. 99 f., il. Dissertação (Mestrado em Educação) - Programa de Pós-Graduação em Educação, Centro de Ciências da Educação, Universidade Regional de Blumenau, Blumenau, 2012. Disponível em: <http://www.bc.furb.br/docs/DS/2012/351091_1_1.pdf>. Acesso em: 11 ago. 2017.

\section{NOTAS}

${ }^{1}$ A Declaração Universal dos Direitos Linguísticos, da qual o Brasil é signatário, foi promulgada em 1996, em Barcelona, durante a Conferência Mundial de Direitos Linguísticos. Disponível em < http://www.letras.ufscar.br/linguasagem/edicao21/pdfs/declaracao.pdf>. Acesso em: 25 fev. 2018.

${ }^{2}$ Optamos por utilizar "língua adicional" e não "estrangeira" em consonância com uma tendência da Linguística Aplicada em posicionar-se de forma crítica diante do ensino de línguas e da educação linguística. Nesse sentido, o usuário da língua não é um estranho à língua, mas "alguém que, por opção ou exposição, aprende uma língua ou mais, além da sua materna, não denotando uma língua como inferior à outra, ou de valor simbólico diferente" (NICOLAIDES; TILIO, 2013, p. 285). No contexto foco da pesquisa, há línguas de imigração que não podem ser vistas como estrangeiras, pois são línguas faladas no território brasileiro em função de um processo histórico, político e identitário que não pode ser apagado.

${ }^{3}$ É necessário reconhecer a existência de povos indígenas no Vale do Itajaí antes da imigração europeia, que, como é sabido, não foram considerados pelo governo brasileiro no processo colonizador. No entanto, pela necessidade de se delimitar o tema de investigação, a pesquisa abrange as línguas de imigração ainda presentes na Microrregião de Blumenau hoje. No alto Vale do Itajaí, ainda há a presença de população indígena Xokleng, conforme Brighenti (2013). Disponível em < https://leiaufsc.files.wordpress.com/2013/08/povosindc3adgenas-em-santa-catarina.pdf >. Acesso em: 25 fev. 2018.

${ }^{4}$ Associação Comercial e Industrial de Blumenau.

${ }^{5}$ Todos os dados referentes ao número de habitantes são relativos ao censo de 2010 , disponíveis na página do IBGE (2010): <http://www.cidades.ibge.gov.br/xtras/uf.php ?lang $=\&$ coduf $=42 \&$ search $=$ santa-catarina $>$. Acesso em: 09 ago. 2017. Parte de outras informações aqui contidas foi retirada das páginas da prefeitura de cada município.

${ }^{6}$ Todos os procedimentos metodológicos utilizados no desenvolvimento da pesquisa ora relatada obedeceram aos procedimentos éticos estabelecidos para a pesquisa científica em Ciências Humanas.

${ }^{7}$ As Secretarias Municipais ofertam somente o ensino fundamental, enquanto as GERED abrangem o ensino fundamental e médio. 
${ }^{8}$ A secretaria municipal de Botuverá oferta somente educação infantil e não há no currículo desse segmento língua adicional.

${ }^{9}$ A LDB e documentos oficiais usam línguas estrangeiras. Optamos, porém, por razões já expostas anteriormente (nota 3), tratar essas línguas como adicionais.

${ }^{10}$ De acordo com os dados do questionário, das 50 escolas municipais de Blumenau, 45 oferecem uma língua adicional. Dessas, sete escolas oferecem apenas a Língua Alemã, 25 apenas a Língua Inglesa e 13 escolas oferecem as duas línguas (Alemão e Inglês). Portanto, do total de 50 escolas, cinco não oferecem nenhuma língua adicional. Por este motivo, no quadro acima, somando as duas colunas referentes ao número de escolas que oferecem apenas uma língua adicional (segunda coluna) e as escolas que oferecem duas ou mais (terceira coluna), o número totaliza 243 escolas e não 248, que é o número total de escolas dos 13 municípios e das gerências que participaram da pesquisa.

${ }^{11}$ A língua guarani é ofertada no município de Major Gercino, onde há uma escola indígena. Ela foi mencionada no questionário da GERED de Brusque pelo fato de o município pertencer a essa Gerência. No entanto, como o município não se localiza na Microrregião de Blumenau, esse dado não será discutido no presente artigo.

${ }^{12}$ No Vale do Itajaí e outras regiões do Sul do Brasil, havia todo um sistema de escolas comunitárias e religiosas teuto-brasileiras. Em muitas dessas escolas, o alemão não era apenas uma disciplina curricular, mas a própria língua de instrução. Há vários registros de escolas na Microrregião em que havia o que podemos chamar hoje de educação bilíngue. (MAILER, 2003; KREUTZ, 2003; FRITZEN; RISTAU, 2013).

${ }^{13}$ Quatro instituições não responderam à pergunta. As respostas foram transcritas conforme foram escritas nos questionários.

${ }^{14}$ Existem escolas rurais que também ofertam a língua alemã na educação infantil, conforme pesquisa anterior (MAAS; FRITZEN; AVELINO NETO, 2014). No entanto, no questionário respondido pela Secretaria, foi informado apenas um centro de educação infantil. Provavelmente pelo fato de essas escolas atenderem até o $5^{\circ}$. ano e terem sido mencionadas no ensino fundamental.

${ }^{15}$ Conforme pesquisas anteriores (FRITZEN, 2007, 2012), a alteração da política linguística se deu a partir de 2002 no município. As novas diretrizes não se referem, portanto, a uma nova política linguística para o município, pois as línguas ofertadas e o modo de oferta continuam os mesmos (vide ainda MAILER, 2003).

Submetido: 03/04/2016

Aprovado: 28/11/2017

Contato:

Maristela Pereira Fritzen

Rua Timbó, 155, apart. 904

Blumenau|SC|Brasil

CEP 89.012-180 
ANEXO

QUESTIONÁRIO - POLÍTICAS DE EDUCAC̦ÃO LINGUÍSTICA NA

MICRORREGIÃO DE BLUMENAU

\section{DADOS:}

1. Seu nome:

2. Telefone para contato:

3. Secretaria de Educação em que atua:

4. Cargo:

5. Atua neste cargo desde (ano/mês):

\section{SOBRE AS ESCOLAS}

1. Quantas escolas da educação básica (ensino fundamental e médio) compõem o sistema de ensino da Secretaria?

$\mathrm{R}:$

2. Além da disciplina de Língua Portuguesa, atualmente, no currículo, quais são os outros idiomas oferecidos? Pode-se assinalar mais de um.

( ) Inglês

( ) Alemão

( ) Italiano

( ) Espanhol

( ) Outro:

3 Quantas escolas oferecem mais de um idioma?

$\mathrm{R}:$ 
4. Desde quando essa(s) língua(s) passou(ram) a compor o currículo escolar?

$\mathrm{R}:$

5. Todas as escolas do sistema oferecem esse(s) idioma(s)?

( ) $\operatorname{Sim}$

( ) Não

6. Quantas são as escolas que oferecem cada idioma:

Inglês

Alemão

Italiano

Espanhol

Outro (

7. A partir de que ano?

Ensino Fundamental

( ) $1^{\circ}() 2^{\circ}() 3^{\circ}() 4^{\circ}\left(\right.$ ) $5^{\circ}() 6^{\circ}\left(\right.$ ) $7^{\circ}\left(\right.$ ) $8^{\circ}() 9^{\circ}$

Ensino Médio

( ) $1^{\circ}\left(\right.$ ) $2^{\circ}() 3^{\circ}$

8. Quantas escolas oferecem:

Um idioma além do português:

Qual?

Dois idiomas além do português:

Quais? 
8.1 Assinale a recorrência dos idiomas semanais:
Inglês
( ) 1 aula
( ) 2 aulas
( ) 3 aulas
( ) 4 aulas
Alemão
( ) 1 aula
( ) 2 aulas
( ) 3 aulas
( ) 4 aulas
Italiano
( ) 1 aula
( ) 2 aulas
( ) 3 aulas
( ) 4 aulas
Espanhol
( ) 1 aula
( ) 2 aulas
( ) 3 aulas
( ) 4 aulas
Outro
( ) 1 aula
( ) 2 aulas
( ) 3 aulas
( ) 4 aulas

8.2 Qual é carga horária de cada aula?

$\mathrm{R}:$

8.3 De que maneira essa(s) aula(s) é(são) oferecida(s)?

( ) Na Matriz Curricular, no período comum de aulas

( ) São oferecidas no contraturno

( ) São oferecidas de forma extracurricular

( ) Outra:

SOBRE OS CENTROS OU UNIDADES DE EDUCAÇÃO INFANTIL

1. Quantos Centros ou Unidades de Educação Infantil compõem o sistema de ensino da Secretaria/GERED?

$\mathrm{R}:$

2. Além da disciplina de Língua Portuguesa, atualmente, no currículo, quais são os outros idiomas oferecidos? Pode-se assinalar mais de um.
( ) Inglês
( ) Espanhol
( ) Alemão
( ) Outro:
( ) Italiano 
3. Quantos Centros ou Unidades de Educação Infantil oferecem mais de um idioma?

$\mathrm{R}:$

4. Desde quando essa(s) língua(s) passou(ram) a compor o currículo escolar?

R:

5. Todos os Centros ou Unidades de Educação Infantil do sistema oferecem esse(s) idioma(s)?

( ) $\operatorname{Sim}$

( ) Não

6. Quantos são os Centros ou Unidades de Educação Infantil que oferecem cada idioma:

Inglês

Alemão

Italiano

Espanhol

Outro

7. A partir de que ano?

( ) Creche

( ) Pré-escola 
8. Assinale a recorrência dos idiomas semanais:
Inglês
( ) 1 aula
( ) 2 aulas
( ) 3 aulas
( ) 4 aulas
Alemão
( ) 1 aula
( ) 2 aulas
( ) 3 aulas
( ) 4 aulas
Italiano
( ) 1 aula
( ) 2 aulas
( ) 3 aulas
( ) 4 aulas
Espanhol
( ) 1 aula
( ) 2 aulas
( ) 3 aulas
( ) 4 aulas
Outro
( ) 1 aula
( ) 2 aulas
( ) 3 aulas
( ) 4 aulas

9. Qual é carga horária de cada aula?

$\mathrm{R}:$

10. De que maneira essa(s) aula(s) é(são) oferecida(s)?

( ) Na Matriz Curricular, oferecidas no período comum de aulas

( ) São oferecidas no contraturno

( ) São oferecidas de forma extracurricular

( ) Outra:

\section{SOBRE DOCUMENTOS REFERENTES AO ENSINO DE LÍNGUAS}

1. A secretaria possui alguma lei, resolução ou documento que se refere à oferta do ensino de línguas no município?

( ) $\operatorname{Sim}$

( ) Não

2. Em caso afirmativo, que documentos seriam esses? Eles podem ser acessados por todos? Se sim, de que modo?

$\mathrm{R}:$ 
3. Qual foi a última mudança ocorrida com relação ao ensino de línguas no município?

( ) Foi implementada nova política linguística

Quando?

( ) Houve adoção de novos livros didáticos

Quando?

( ) Foram redigidas novas diretrizes curriculares

Quando?

( ) Outro:

Quando?

\subsection{Por quê?}

$\mathrm{R}:$

4. Você teria mais alguma informação que considera relevante sobre esse assunto?

$\mathrm{R}:$ 